\title{
Risk management in construction sphere
}

\author{
Liudmila Kaverzina ${ }^{1 *}$,Elena Litvin ${ }^{2}$, Victoria Dorofeeva ${ }^{3}$, and Valentina Nikiforova ${ }^{1}$ \\ ${ }^{1}$ Bratsk state university, Makarenko str., 40, Bratsk, Russia \\ ${ }^{2}$ Sberbank PJSC, Vavilova st.,19, Moscow, Russia \\ ${ }^{3}$ Kaliningrad State Technical University, Ave. Soviet, 1, Kaliningrad, Russia
}

\begin{abstract}
In modern terms of housekeeping complicated by coronavirus infection and crisis phenomena in world and Russian economics, there is a high probability of different risks occurrence, connected with activity of modern enterprises in investment and construction sphere. Success, profit and efficiency of enterprise activity in current situation in many ways depends on ability to manage appearing risks to minimize them. It confirms relevance of the research which results are performed in this article. Purpose of the research is to reveal priority directions of management actions aimed to production, financial, logistics, investment and other processes functioning in regional investment and construction sphere, and also to develop mechanism of risk management, which allows to provide reducing of risk appearance probability and minimize their effects. Authors have assessed state Irkutsk region's investment and construction complex, determined the most likely risks of construction activity. It has been determined the essence of "risk" concept, and systematization of risks in investment and construction processes has been implemented. Mechanism of construction enterprise's risk management has been developed. The methodological base for research are general scientific methods of understanding the processes of construction products: observation, generalization, comparison, grouping, as well as methods of logical, economical and system analysis.
\end{abstract}

\section{Introduction}

Activity of enterprises, functioning in the investment and construction sphere, is often connected with uncertainty and risk, which appears in specific financial and economical conditions of housekeeping and aggravated by a number of factors. Nowadays, the most significant risk for housekeeping subjects is the pandemic caused by coviid-19 infection, which has worsened the financial and economical situation in whole world. Due to this fact, there is the rise in relevance of solvation of problematic issues in risk management of the construction sphere including regional investment and construction complex and also individual construction enterprises.

*Correspondingauthor: Dekanfps@mail.ru 
Issues of risk management in construction sphere have always been under close watch of both academic theorists and practitioners. [1-5]. Special attention is paid to risk management problems in terms of economical crisis and financial instability $[6,7]$.

The modern terms of housekeeping are objectively demand creation of complex system of risk management at enterprises related to construction production. [8]. Main purpose of functioning of created system is minimization of risks [9], at the same time the role of control rises in process of risk management directly at construction enterprises [10]. Though the research of theoretical aspects of risk management as well as solvation of practical problems has been conducted by foreign (T. Barton, F. Broony, A. Castle, A. Marshall, M. Mescon, M. Freedman, V. Hoyer, Y. Shumpeter) and Russian (A. Asaul, A. Druzenko, G. Sherbina, T. Shvedkova, I.Balabanov, B. Riseberg, D. Tulin and others) economists, individual sectoral scientific and methodological aspects are insufficiently worked out and demand further studying.

After reviewing publications on the issues discussed in article, we may conclude that there is a rise relevance of solving problems connected to risk management in construction sphere in modern conditions.

Relying on the conclusion, the authors of the article have determined aim of their research: revealing of main management influences on different processes, which take place at construction enterprises; implementing of those influences in terms of developed author's mechanism, which will allow to minimize appearing risks.

The object of the research are construction enterprises and other organizations included in the investment and construction complex.

Subject of the study are financial, organizational, economical, and other relations appearing in the process of construction enterprises functioning and their further development under the influence of market factors, which increase risks of producing activity in modern conditions.

\section{Research methods}

Methodological base of the conducted research are general scientific methods of social and economical processes' cognition, namely observation, analysis, generalization, comparison. Also elements of system and complex approaches have been used.

During the analysis of interpretation of the concept "risk" by different economists have been used such general scientific methods as generalization and comparison as well as method of logical analysis. As a result, author's definition of studied concept has been proposed.

During systematization of risks, appearing in implementing of activity of enterprises of the investment and construction complex, methods of scientific search and classification have been used. Eventually, it has been proposed to combine all risks appearing during the process of construction into 6 groups.

During assessment of probability of different types of risks in modern enterprises' activities of construction sphere, functioning in Irkutsk region, it have been used methods of economical, logical and system analysis, as well as the method of expert assessments. Usage of these methods has allowed to detect the most probable risks in construction sphere in modern terms of housekeeping, complicated by coronavirus pandemic (covid-19), crisis phenomena in global economics, regional problems and other factors.

Analytical work about problematic issues studying in the article have been conducted by the authors according to the information provided by The territorial body of the Federal State Statistics Service for the Irkutsk region. 


\section{Results}

Conducted by the authors research has allowed to get the following results:

1. The content side of the concept "risk" has been studied and author's interpretation of the concept has been proposed;

2. Systematization of risks, appearing at enterprises functioning in the investment and construction sphere has been implemented;

3. It has been assessed the condition of the investment and construction complex of Irkutsk region.; risk factors of construction activity have been detected; the most probable risks of regional investment and construction business in modern terms have been determined;

4. Mechanism of risk management at construction enterprise has been developed.

Let's consider the obtained results in more detail.

1. Before talking about risk management at any level of housekeeping, it is necessary to clearly decide the "risk" definition. In modern economic publications there are huge variety of definitions of "risk". Reviewing the definitions proposed by different authors, we can conclude that many authors consider that risk is a possible probability of losses. However, overviewing the "risk" definition we suppose that it is expedient to clarify as a result of which it appears. According to this, we propose the following definition of studied concept - it is generalized characteristic of the probable or actually emerging as a result of realization of certain management decisions undertaken by individuals, accepting these decisions for a specific housekeeping subject, and aimed at achieving the set goals.

In the investment and construction sphere investors, customers, contractors and enterprise directors involved in production of construction products may make decisions within their competence. As a generalized characteristic we can use one indicator or system of indicators which characterize result of certain situation's development, which is the consequence of accepting certain management decisions.

2. The overview conducted by the authors, which is dedicated to consideration of risks directly in construction sphere [11-13], allows to conclude that enterprises face many kinds of risks which require managing. Namely: technical, investment, economical, ecological, manufacturing, operational, innovative, geotechnical, financial, judicial, taxing, logistical, entrepreneurial, informational, social, bank, credit and other risks. Such a variety of risks in activity of construction enterprises involved in manufacturing of construction products require its systematization. Authors of the conducted research suggest to unite all listed risks into the following groups:

1) Risks appearing at the stage of projecting and preparing of construction;

2) Risks appearing at the stage of manufacturing of construction products;

3) Risks appearing in the process of implementing of organizational and management activity;

4) Financial, social and economical risks;

5) Informational and legal risks;

6) Other risks.

The first group includes project and geotechnical risks, minimization of which largely determines success of the construction activity.

The second group includes manufacturing, technical and innovational risks.

The third group includes organizational and technological (operational) risks.

The fourth group includes social, economical, financial, bank, credit, taxing and investment risks.

The fifth group includes judicial and informational risks

The sixth group includes such risks as ecological, emergency and others. 
3. The authors of the conducted research have analyzed the state of investment and construction complex of Irkutsk region. As a result, the most probable regional risks of the investment and construction activity in modern conditions have been determined. In these number we can firstly mark risks of the fourth group, namely: investment, financial and credit risks complicated by uncertainty of economical situation in country as a whole and in the studied region in particular.

Periodically, the conducted analysis of regional state of the investment and construction complex [14-16] allows to conclude that Irkutsk region has problems which hold back the construction and its untimely solvation increases risks of the investment and construction activity in the region.

4. The authors have proposed the mechanism of risk management at construction enterprise, which is presented as a scheme (Figure 1).

This mechanism suppose creation at construction enterprise the system of risk management, which unites 5 elements: target, tasks, functions, stages and tools.

The first element of the risk management system (target of risk management) is realized by subject of management's determination of tasks, methods and means of its achieving. The process of risk management would be more efficient if we choose not one target, but plenty of them connected to each other logically and considering content multidirectionality of appearing risks, determining by factors of outer and inner environments of its functioning.

Targets determining by enterprise in the system of risk management should satisfy certain requirements, namely:

- should be clearly articulated and commensurate with each other; should be achievable and flexible (have clearly established terms of its achievement and justification of resource capabilities, and also must be the opportunity to its correction to take into account the changes occurring in inner and outer environments changes, which influence the probability of appearing of any kind of risks and its predicted value);

- should be targeted and controlled, which require determination of certain personalities responsible for its achievement and constant monitoring of the process of progress towards the set target.

The first element of author's mechanism of risks management means construction A "goal tree" and development of several alternative options among which it will be chosen the most suitable in option.

Successful achievement of aimed goals will be facilitated by clear formulation of the tasks requiring solvation, which determined in terms of the second element of the proposed mechanism. Among the priority tasks requiring solvation, there are the following tasks:

- timely detection of risk factors for an enterprise and definition of probability and threat level of identified factors ;

- Development of the risk management policy, defining strategy and tactics of dealing with risks;

- Development of measures to reduce the probability of risks appearing, preparation of conditions for its realization, implementing of the control tasks and result analysis.

The list of tasks solving by certain construction enterprise may be clarified depending on current activity conditions causing certain risks.

The third element of the studied mechanism is functions of the risks management system. Its list is traditional for management processes.

The fourth element is the most significant in the risk management mechanism and it is called "stages of risk management process" This element include 6 connected to each other stages:

I stage. Analysis of inner and outer environment of the enterprise which means detection of risk factors. 


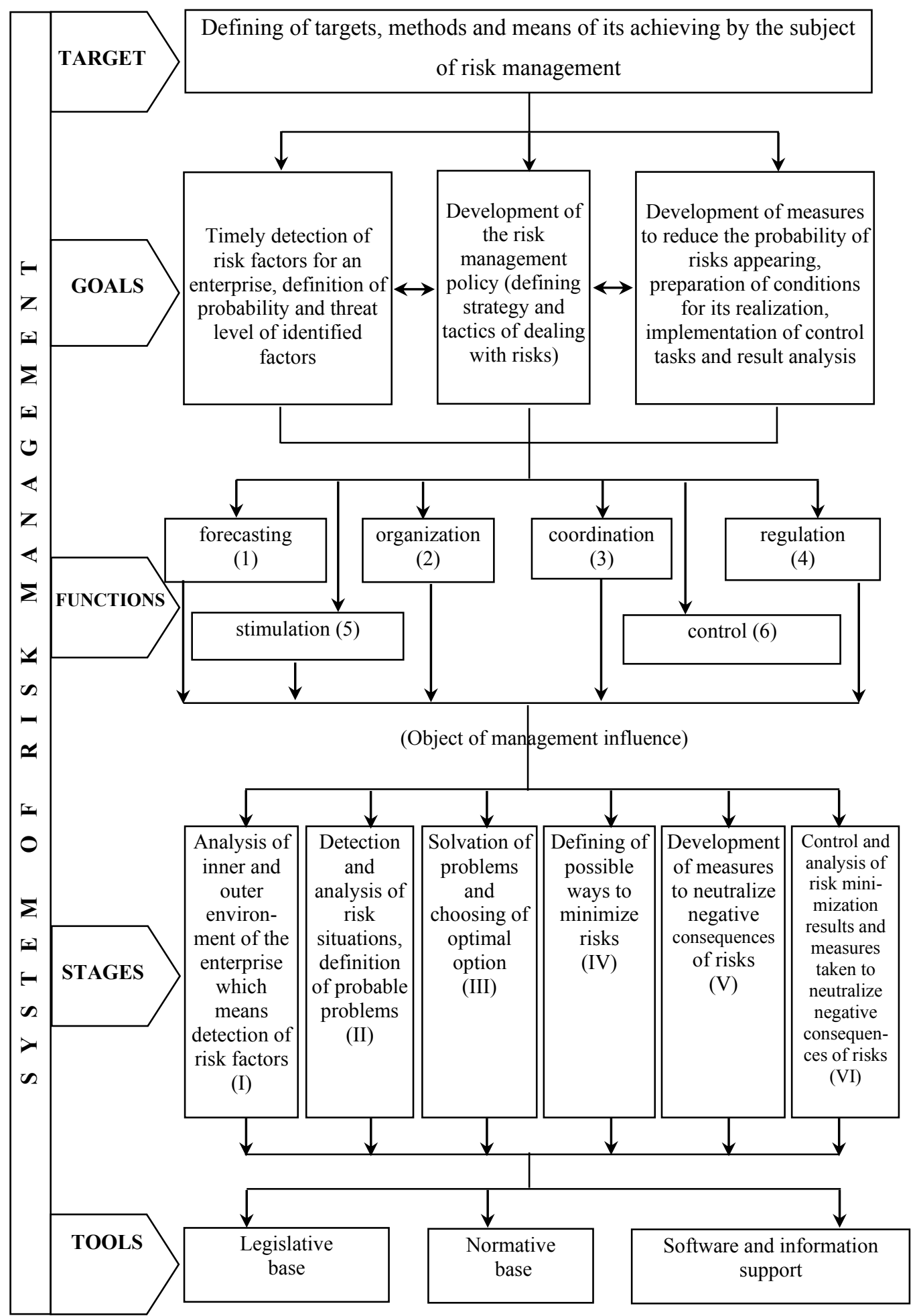

Fig. 1. The mechanism of risk management at construction enterprise 
II stage. Detection and analysis of risk situations, definition of probable problems.

III stage. Solvation of problems and choosing of optimal option.

IV stage. Defining of possible ways to minimize risks.

V stage. Development of measures to neutralize negative consequences of risks.

VI stage. Control and analysis of risk minimization results and measures taken to neutralize negative consequences of risks

The fifth and final element of the mechanism is tools of the risk management system (regulatory, legislative and legal framework and software and information support).

Using software and information support involves availability of information base presented in modern form and including several subsystems, which management is implementing by enterprise management's automation service's specialists. In terms of the digitalization development of different aspects of modern enterprises activity, it is possible to use blockchain, BIM and other technologies.

Practical usage of the proposed mechanism of risks management will allow to effectively implement management process at construction enterprises, minimizing and in some cases nullifying different risks of the investment and construction activity.

\section{Discussion}

Certain elements of the studied issues are controversial. For instance, the definition of 'risk' concept and its essence is widely discussed by modern scientists. $[12,13,17,18]$. The definition proposed by the authors of the conducted research (results of which are presented in current article), overviews risk as a result of some management activity, by changing which it is possible to directly manage the appearing risks and increase the efficiency of this process.

Issue of risks classification is also often considered in publications $[1,11,17,19]$. Different classification features and corresponding types of risks are proposed. Distribution into 6 groups conducted by the authors allows not only systematize risks, but define expedient and efficient management actions for risk minimization.

The highly discussed by modern scientists, is the issue connected to development of the efficient mechanism of risk management in construction sphere [20-22]. Risk management mechanism at construction enterprise presented in this article, allows to systematize the overviewed process, standing out main stages, determining targets, goals, functions and tools.

It is necessary to note that in conditions of economy digitalization, the issue of using modern digital tools (digital technologies) during the process of risk management is also controversial, which is confirmed by publications of different authors [23-27].

Discussion of all listed issues will allow to find optimal ways to minimize risks of the investment and construction activity

\section{Conclusion}

Nowadays, risk management is an actual target in construction sphere. The conducted research has allowed to develop theoretical knowledge about the essence of "risk" concept and also systematization of risks, appearing at enterprises functioning in the investment and construction sphere.

Practical significance of presented results of the scientific research is as follows:

- developed mechanism of risk management at construction enterprises allows to approach complexly to implementation of studied management process; 
- stage-by-stage realization model of the developed mechanism allows to optimize management actions aimed to smoothing emerging risk situations at certain enterprise;

- timely detection of different risk factors allows to forecast the development of risk situations and clearly determine probability and threat level of defined factors. Using this information, company managers can develop complex of measures for liquidation of forecasting problems and minimization of possible damage.

\section{References}

1. A. S. Solov'eva, I. P. Frolova, E. I. Zagainova, Intellect. Innovation. Investments., 10, 32-36 (2017)

2. M. V. Levchenko, Risk Management, 1, 29-34 (2019)

3. I. P. Frolova, Economics and Management of Innovative Technologies, 12, 9 (2018)

4. I. Yu. Maloletkov, Economics and Entrepreneurship, 12-2, 568-571 (2017)

5. E. M. Popova, O. N. Tyulyaev, Banking Services, 6, 34-40 (2014)

6. M. M. Assayra, Engineering Bulletin of the Don, 1, 160 (2018)

7. E. N. Grishchenko, I. P. Avilova, Innovative Science, 1-1, 36-38 (2017)

8. M. M. Kostyshak, S. S. Lyashko, Economics and Entrepreneurship, 7, 1227-1231 (2018)

9. V. G. Borkovskaya, Vestnik MGSU, 13, 11, 1341-1348 (2018) DOI: 10.22227/19970935.2018.11.1341-1348

10. L. Z. Baiguzina, E. H. Baranova, Trends in the development of science and education, 66-3, 96-98 (2020) DOI: 10.18411/1j-10-2020-116

11. E. A. Kainov, N. I. Shaibakova, Scientific and practical research, 5.1 (20), 13-22 (2019)

12. N. V. Postnikova, Scientific Journal, 4, 35-37 (2020)

13. B. G. Kim, Z. N. Shakir, Prospects of Science, 7, 131-134 (2019)

14. L. A. Kaverzina, M. I. Cherutova, I. P. Nuzhina, IOP Conf. Ser.: Mater. Sci. Eng., 953012053 (2020) doi:10.1088/1757-899X/953/1/012053

15. L. Kaverzina, MATEC Web Conf., 21208030 (2018) DOI: $10.1051 /$ matecconf $/ 201821208030$

16. L. Kaverzina, P. Koshevoi, V. Dorofeeva IOP Conf. Ser.: Mater. Sci. Eng., 667 012037 (2019) DOI: 10.1088/1757-899X/667/1/012037

17. A. Zanko, Science and Innovation, 12, 49-53 (2016)

18. A. N. Shelaykina, R. G. Abakumov, Innovative economy: prospects for development and improvement, 1, 314-318 (2016)

19. D. V. Yevtushenko, E. A. Butenko, Competitiveness in the global world: Economics, Science, Technology, 6-3, 49-51 (2017)

20. V. A. Gordash, A. N. Korkishko, Economics and Entrepreneurship, 1, 646-649 (2020)

21. M. V. Kuznetsova, N. S. Ivashina, Economics and Business: Theory and Practice, 122, 5-9 (2018) DOI: 10.24411/2411-0450-2018-10247

22. E. Y. Kulikova, Gorny Information and Analytical Bulletin, 6-1, 128-136 (2020) DOI: 10.25018/0236-1493-2020-61-0-128-136

23. S. S. Korabelnikova, S. K. Korabelnikova, Discussion, 2, 18-27 (2019)

24. M. A. Privalova, N. S. Korepanova, A. L. Kuznetsov, I. V. Simchenko, Intelligent systems in production, 18 2, 96-105 (2020) DOI: 10.22213/2410-9304-2020-2-96-105

25. N. G. Abdukhanova, G. D. Kamaletdinova, G. R. Zeynetdinova, Finance and Credit, 25 8, 1907-1917 (2019) DOI: 10.24891 / fc. 25. 8. 1907

26. A. M. Patrusova, M. Y. Vahrusheva, IOP Conf. Ser.: Mater. Sci. Eng., 753082028 (2020) DOI: 10.1088/1757-899X/753/8/082028

27. P. V. Gorbulin, Estimate and contract work in construction, 7, 40-47 (2019) 